\title{
EDITORIAL
}

\section{Fluid management in diabetic ketoacidosis: new tricks for old dogs?}

\author{
Bruno Adler Maccagnan Pinheiro Besen ${ }^{1,2^{*}} \mathbb{D}$, Willem Boer ${ }^{3}$ and Patrick M. Honore ${ }^{4,5}$
}

๑ 2021 Springer-Verlag GmbH Germany, part of Springer Nature

Some treatment recommendations in medicine stem from guidelines based on expert opinion, anecdotal reports and pathophysiological rationale. In one such entity, diabetic ketoacidosis (DKA), pathophysiological rationale and expert opinion have guided treatment recommendations with limited experimental scrutiny in the form of randomized clinical trials. While fluid therapy is a cornerstone of the management of DKA, the recommendations on the volume, rate and of type of fluid to be administered are based on scarce experimental data. In this issue of Intensive Care Medicine, Ramanan et al. report the results of the SKOPE-DKA cluster-crossover phase 2 randomized clinical trial comparing Plasmalyte (PL) to $0.9 \%$ sodium chloride (SC) in the management of patients admitted to the intensive care unit (ICU) with DKA [1].

The current American Diabetes Association (ADA) guidance on the management of DKA recommends using $0.9 \%$ SC initially as a $15-20 \mathrm{~mL} / \mathrm{Kg}$ bolus for hemodynamic resuscitation and then $250-500 \mathrm{~mL} / \mathrm{h}$ of fluid until glucose is normalized (usually faster than DKA resolution) and then $150-250 \mathrm{~mL} / \mathrm{h}$ until DKA resolution [2]. For the replenishment solution after the bolus, the guideline recommends using $0.45 \%$ SC unless hyperglycemia-corrected hyponatremia is present. For this recommendation, no clinical trial is referenced [2]. Actually, one reference suggests colloids should be the preferred fluid administered, while acknowledging $0.9 \%$ SC would be a good compromise to replenish the fluid losses of patients with DKA [3]. Another reference from prior

\footnotetext{
*Correspondence: brunobesen@yahoo.com.br

${ }^{1}$ Medical ICU, Disciplina de Emergências Clínicas, Hospital das Clínicas HCFMUSP, Faculdade de Medicina, Universidade de São Paulo, São Paulo, SP, Brazil

Full author information is available at the end of the article
}

guidance, which is based on descriptive information of 29 episodes on 26 subjects, suggests that the loss of water is greater than sodium, which is nevertheless greater than the chloride losses [4], which raises the intriguing question whether the use of balanced solutions might be beneficial. Surprisingly, these are a glimpse of the reports that have been guiding fluid management in DKA for decades.

Some authors have postulated that the use of balanced solutions instead of $0.9 \% \mathrm{SC}$ in the management of DKA may avoid concurrent hyperchloremic acidosis (HA), a known side effect of unbalanced solutions, and shorten time to DKA resolution [5]. Though HA has been shown to be a common issue during the treatment of DKA [6], others argue that HA in DKA is not necessarily related to the type of fluid administered, but due to renal handling of bicarbonate and sodium and other issues [7]. A large pediatric multicenter factorial DKA trial studied the tonicity $(0.45 \%$ vs. $0.9 \% \mathrm{SC})$ and volume/rate of administration of fluid [8]. The primary outcome was neurological deterioration, which was not different between groups, nor were there differences in medium to long term cognitive outcomes. However, HA was observed in the $0.9 \%$ SC (compared to $0.45 \%$ ) and the fast treatment groups, suggesting these could be relevant issues during the treatment of DKA.

In adults, reports about fluid management in DKA include the recent sub analyses of the SALT-ED and SMART trials, which showed a hastened time to DKA resolution and time to cessation of insulin infusion when using any balanced crystalloid [9]. Another, albeit small, clinical trial published in 2012 demonstrated that ringer lactate did not lead to hastened correction of $\mathrm{pH}$ compared to $0.9 \% \mathrm{SC}$, but that there was a lower correction rate of glucose levels in spite of the same amount of insulin administered per hour [10]. Finally, another small clinical trial published in 2011 demonstrated that PL,

\section{Springer}


Fluid management in Diabetic Ketoacidosis: what effects can it take?

\begin{tabular}{|c|c|c|c|c|}
\hline $\begin{array}{l}\text { Fluid } \\
\text { intervention }\end{array}$ & $\begin{array}{l}\text { Immediate } \\
\text { effects }\end{array}$ & $\begin{array}{c}\text { Short-term clinical } \\
\text { outcomes }\end{array}$ & $\begin{array}{l}\text { System-centered } \\
\text { outcomes }\end{array}$ & $\begin{array}{l}\text { Long-term } \\
\text { outcomes }\end{array}$ \\
\hline $\begin{array}{l}\text { Fluid type: } \\
\text { 1. } 0.9 \% \text { Sodium } \\
\text { chloride } \\
\text { 2. Plasmalyte }{ }^{\circ} \\
\text { 3. Ringer lactate } \\
\text { Fluid tonicity } \\
\text { Fluid rate } \\
\text { Fluid volume }\end{array}$ & $\begin{array}{l}\text { Hyperchloremic } \\
\text { acidosis } \\
\text { Persisten } \\
\text { dehydration } \\
\text { Fluid shifts } \\
\text { Ketoacids } \\
\text { metabolization } \\
\text { Fluid } \\
\text { accumulation }\end{array}$ & $\begin{array}{c}\begin{array}{c}\text { Acute kidney } \\
\text { injury }\end{array} \\
\begin{array}{c}\text { Arterial thrombotic } \\
\text { events }\end{array} \\
\text { Cerebral edema } \\
\text { Time to DKA } \\
\text { reversal } \\
\text { ICU and hospital } \\
\text { mortality }\end{array}$ & $\begin{array}{c}\text { ICU length-of-stay } \\
\text { Hospital } \\
\text { length-of-stay } \\
\text { Hospital } \\
\text { readmission }\end{array}$ & $\begin{array}{l}\begin{array}{l}\text { Chronic kidney } \\
\text { disease }\end{array} \\
\text { Heart failure } \\
\text { Cognitive } \\
\text { impairment } \\
\text { Reduced quality } \\
\text { of life }\end{array}$ \\
\hline
\end{tabular}

Fig. 1 How fluid type, tonicity, rate and volume may impact outcomes in patients with severe diabetic ketoacidosis. The fluid variables have shortlived physiological effects, such as hyperchloremic acidosis or fluid accumulation that may be associated to short-term clinical outcomes, such as acute kidney injury, thrombotic events, cerebral edema and the most commonly used outcome of DKA reversal. ICU and hospital mortality are unlikely events in DKA and probably are hardly modulated by different fluid strategies. Through these events, length-of-stay or readmissions may be shorter or less frequent. Finally, the impact on long term clinical outcomes of having a faster or slower resolution of DKA and a complicated or uncomplicated admission for DKA can also be studied. All these outcomes would probably be better scrutinized in a platform adaptive trial, where many interventions (fluid related or not) could be studied and patients followed-up for enough time after discharge to evaluate long-term outcomes. DKA diabetic ketoacidosis; ICU intensive care unit

compared to $0.9 \% \mathrm{SC}$, improved bicarbonate concentrations faster by avoiding an overlapping HA during treatment [11]. Unfortunately, this experimental evidence still has not been translated to guidelines and neither to clinical practice.

Ramanan et al. bring needed evidence in their report of the results of SKOPE-DKA cluster-crossover clinical trial [1]. The authors defined DKA resolution as base excess correction at $48 \mathrm{~h}$. There was no difference at $48 \mathrm{~h}$, but there was a difference at $24 \mathrm{~h}$, with resolution in over two thirds in the PL group compared to just over a third in the SC group. Ketoacid and anion-gap correction-the strongest markers of DKA correction-were not different between groups and hospital length-of-stay was the same between groups. The immediate implications are that $0.9 \%$ SC has no deleterious effects on DKA resolution itself, but that SC fluid therapy does add HA during treatment [12]; and that acetoacetate from PL does not impair ketoacid elimination, although it is metabolized through this metabolic pathway. Whether these small physiological benefits translate into improved patient centered outcomes or at least to a shortened ICU and total hospitalization duration remains unclear, but the case for using balanced solutions, such as PL seems stronger. Nevertheless, the recently published BaSICS trial assessing PL against $0.9 \%$ SC on critically ill patients' 90 -day mortality is a reminder of the need to randomize to accumulate enough evidence to have realistic expectations from fluid effects on critically ill patients overall and in important subgroups [13].

The trial has its limitations due to its small sample size and its open-label design. Adherence to the intervention was not adequate in the intervention (PL) group (only about $2 / 3$ received PL in that group), especially in the emergency department before ICU admission, this despite a cluster trial design to enhance uptake of intervention and avoid contamination. Explanations may include the absence of blinding, unfamiliarity of ED physicians with PL and lack of training and education about the trial equipoise and procedures, which are important considerations in the design of a larger trial.

Future research in DKA fluid management should include not only the type of fluid, but also the total volume and rate of administration, important variables that may affect the speed of DKA resolution. Outcomes to be measured should include not only DKA resolution, but hospitalization duration (a system centered outcome), acute kidney injury incidence [14], neurological and coronary adverse events [15] and, if possible, more medium to long term outcomes, such as chronic kidney disease development due to concerns with chloride-rich solutions. Finally, modern approaches for 
clinical trial design [16] should be considered to allow testing more than one intervention in a single platform and bring much needed robust experimental evidence to guidelines on fluid management during the treatment of DKA (Fig. 1).

\begin{abstract}
Author details
${ }^{1}$ Medical ICU, Disciplina de Emergências Clínicas, Hospital das Clínicas HCFMUSP, Faculdade de Medicina, Universidade de São Paulo, São Paulo, SP, Brazil. ${ }^{2}$ Intensive Care Unit, Hospital A.C. Camargo Cancer Center, São Paulo, SP, Brazil. ${ }^{3}$ Intensive Care Department, Ziekenhuis Oost Limburgh, Campus St Jan, Genk, Belgium. ${ }^{4}$ Co-Director at the Intensive Care Dept of Brugmann University Hospital, Brussels, Belgium. ${ }^{5}$ Faculty of Medicine, Professor at the ULB University, Brussels, Belgium.
\end{abstract}

\section{Funding}

None.

\section{Declarations}

\section{Conflicts of interest}

$B A M P B, P M H$ and WB report no conflicts of interest related with the content of this editorial.

\section{Publisher's Note}

Springer Nature remains neutral with regard to jurisdictional claims in published maps and institutional affiliations.

Received: 8 August 2021 Accepted: 3 September 2021

Published online: 5 October 2021

\section{References}

1. Ramanan M, Attokaran A, Murray L, Bhadange N, Stewart D, Rajendran G, Pusapati R, Petty M, Garrett P, Kruger P, Peake S, Billot L, Venkatesh B (2021) Sodium Chloride or Plasmalyte-148 Evaluation in severe Diabetic Keto-Acidosis (SCOPE-DKA): a cluster, crossover, randomized, controlled trial. Intensive Care Med. https://doi.org/10.1007/s00134-021-06480-5

2. Kitabchi AE, Umpierrez GE, Miles JM, Fisher JN (2009) Hyperglycemic crises in adult patients with diabetes. Diabetes Care 32:1335-1343

3. Hillman K (1987) Fluid resuscitation in diabetic emergencies-a reappraisal. Intensive Care Med 13:4-8

4. Martin HE, Smith K, Wilson ML (1958) The fluid and electrolyte therapy of severe diabetic acidosis and ketosis; a study of twenty-nine episodes (twenty-six patients). Am J Med 24:376-389
5. Chua HR, Venkatesh B, Stachowski E, Schneider AG, Perkins K, Ladanyi S, Kruger P, Bellomo R (2012) Plasma-Lyte 148 vs $0.9 \%$ saline for fluid resuscitation in diabetic ketoacidosis. J Crit Care 27:138-145

6. Lopes AD, Maciel AT, Park M (2011) Evolutive physicochemical characterization of diabetic ketoacidosis in adult patients admitted to the intensive care unit. J Crit Care 26:303-310

7. Kamel KS, Halperin ML (2015) Acid-base problems in diabetic ketoacidosis. N Engl J Med 372:546-554

8. Kuppermann N, Ghetti S, Schunk JE, Stoner MJ, Rewers A, McManemy JK, Myers SR, Nigrovic LE, Garro A, Brown KM, Quayle KS, Trainor JL, Tzimenatos L, Bennett JE, DePiero AD, Kwok MY, Perry CS 3rd, Olsen CS, Casper TC, Dean JM, Glaser NS, Group PDFS (2018) Clinical trial of fluid infusion rates for pediatric diabetic ketoacidosis. N Engl J Med 378:2275-2287

9. Self WH, Evans CS, Jenkins CA, Brown RM, Casey JD, Collins SP, Coston TD, Felbinger M, Flemmons LN, Hellervik SM, Lindsell CJ, Liu D, mccoin NS, Niswender KD, Slovis CM, Stollings JL, Wang L, Rice TW, Semler MW, Pragmatic Critical Care Research G (2020) Clinical effects of balanced crystalloids vs saline in adults with diabetic ketoacidosis: a subgroup analysis of cluster randomized clinical trials. JAMA Netw Open 3:e2024596

10. Van Zyl DG, Rheeder P, Delport E (2012) Fluid management in diabeticacidosis-Ringer's lactate versus normal saline: a randomized controlled trial. QJM 105:337-343

11. Mahler SA, Conrad SA, Wang H, Arnold TC (2011) Resuscitation with balanced electrolyte solution prevents hyperchloremic metabolic acidosis in patients with diabetic ketoacidosis. Am J Emerg Med 29:670-674

12. Maciel AT, Park M (2009) A physicochemical acid-base approach for managing diabetic ketoacidosis. Clinics (Sao Paulo) 64:714-718

13. Zampieri FG, Machado FR, Biondi RS, Freitas FGR, Veiga VC, Figueiredo RC, Lovato WJ, Amendola CP, Serpa-Neto A, Paranhos JLR, Guedes MAV, Lucio EA, Oliveira-Junior LC, Lisboa TC, Lacerda FH, Maia IS, Grion CMC, Assuncao MSC, Manoel ALO, Silva-Junior JM, Duarte P, Soares RM, Miranda TA, de Lima LM, Gurgel RM, Paisani DM, Correa TD, Azevedo LCP, Kellum JA, Damiani LP, Brandao da Silva N, Cavalcanti AB, Ba Si, the Bm, (2021) Effect of Intravenous Fluid Treatment With a Balanced Solution vs 0.9\% Saline Solution on Mortality in Critically III Patients: The BaSICS Randomized Clinical Trial. JAMA : the journal of the American Medical Association 326(9):818-829

14. Honore PM, Mugisha A, Kugener L, Redant S, Attou R, Gallerani A, De Bels D (2020) The causal link between hyperchloremia and acute kidney injury is yet to be conclusively established: we are not sure. Crit Care 24:271

15. Kaefer K, Botta I, Mugisha A, Berdaoui B, De Bels D, Attou R, Honore PM, Redant S (2019) Acute coronary syndrome and diabetic keto acidosis: the chicken or the egg? Ann Transl Med 7:397

16. Harhay MO, Casey JD, Clement M, Collins SP, Gayat E, Gong MN, Jaber S, Laterre PF, Marshall JC, Matthay MA, Monroe RE, Rice TW, Rubin E, Self WH, Mebazaa A (2020) Contemporary strategies to improve clinical trial design for critical care research: insights from the First Critical Care Clinical Trialists Workshop. Intensive Care Med 46:930-942 